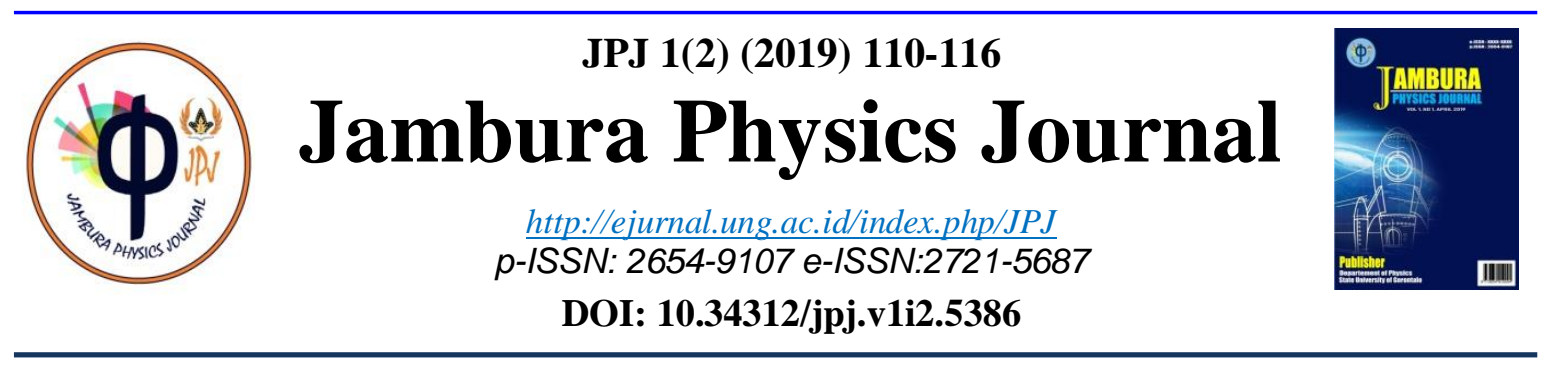

\title{
IDENTIFIKASI STRUKTUR BAWAH PERMUKAAN DI DAERAH PANAS BUMI DESA PANCURAN KECAMATAN SUWAWA SELATAN MENGGUNAKAN METODE GEOLISTRIK KONFIGURASI SHCLUMBERGER
}

\author{
Demulawa M. ${ }^{*}$, Kobi W. ${ }^{2}$ \\ ${ }^{1}$ Jurusan Fisika, Universitas Negeri Gorontalo, Gorontalo \\ ${ }^{2}$ Jurusan Ilmu dan Teknologi Kebumian, Universitas Negeri Gorontalo, Gorontalo
}

Accepted: September 5 2019. Approved: October 09 2019. Published: October 302019

\begin{abstract}
ABSTRAK.
Telah dilakukan penelitian dengan menggunakan metode geolistrik tahanan jenis konfigurasi schlumberger di desa Pancuran kecamatan Suwawa Selatan. Metode ini di gunakan untuk mengetahui besarnya resistivitas setiap lapisan batuan. Softwere yang digunakan untuk mengolah data hasil pengukuran yaitu software IPI2WIN dengan menghasilkan kurva matching 2D. Dari hasil pengolahan data diperoleh tiga lapisan batuan yaitu batu lempung nilai resistivitas sebesar 5,28 $\Omega \mathrm{m}$ dengan ketebalan lapisan $0,9 \mathrm{~m}$, batu pasir nilai resistivitas sebesar $69,3 \Omega \mathrm{m}-$ $185 \Omega \mathrm{m}$ dengan ketebalan lapisan sebesar 9 meter dan andesit memiliki ketebalan $40 \mathrm{~m}$ dengan nilai resistivitas sebesar $21482 \Omega \mathrm{m}$.
\end{abstract}

Kata Kunci: Resistivitas, Konfigurasi Schlumberger; IP2Win.

\section{PENDAHULUAN}

Indonesia secara geologis terletak pada pertemuan tiga lempeng tektonik utama yaitu Lempeng Eropa-Asia, India-Australia dan Pasifik yang berperan dalam proses pembentukan gunung api di Indonesia. Kondisi geologi ini memberikan kontribusi nyata akan ketersediaan energi panas bumi di Indonesia. Manifestasi panas bumi yang berjumlah tidak kurang dari 244 lokasi tersebar di Sumatera, Jawa, Bali, Kalimantan, Kepulauan Nusa Tenggara, Maluku, Sulawesi, Halmahera dan Irian Jaya, menunjukkan betapa besarnya kekayaan energi panas bumi yang tersimpan di dalamnya.

Panas bumi selalu berasosiasi dengan jalur vulkanik dan berada pada daerah gunung api tidak aktif, yang masih menyimpan panas di bawah permukaan. Di

*Alamat Korespondensi

E-mail: meilandemulawa@gmail.com 
Indonesia terdapat 217 prospek panas bumi, yaitu di sepanjang jalur vulkanik mulai dari bagian Barat Sumatera, Maluku, terus ke Pulau Jawa, Bali, Nusa Tenggara dan kemudian membelok ke arah utara melalui Maluku dan Sulawesi. Survei yang dilakukan selanjutnya berhasil menemukan beberapa daerah prospek baru sehingga jumlahnya meningkat menjadi 256 prospek, yaitu 84 prospek di Sumatera, 76 prospek di Jawa, 51 prospek di Sulawesi, 21 prospek di Nusatenggara, 3 prospek di Irian, 15 di Maluku dan 5 prospek di Kalimantan.

Beberapa kelompok panas bumi yang ada di kabupaten Bonebolango yaitu kelompok Libungo terletak di desa Libungo, kelompok Lombongo berada di desa Lombongo dan kelompok Pangi terletak di desa Kayubulan. Panasbumi Suwawa masuk entalpi menengah dengan suhu sekitar 188 derajat Celcius. Selain di tiga desa yang ada satu manifestasi panas bumi yang masuk dalam entalpi rendah yaitu panas bumi yang berada di desa Pancuran. Seperti diketahui, sistem panasbumi menengah memang mendominasi panasbumi di wilayah Sulawesi dan Kalimantan.

\section{LANDASAN TEORI}

\section{Panas Bumi}

Energi panas yang secara alami terbentuk dari beberapa sistem geopressure dan magma berasal dari dalam bumi secara konduksi dan konveksi ditransfer ke permukaan bumi merupakan energi panas bumi. Manifestasi panas bumi yang sering ditemukan dan dimanfaatkan di Wilayah Indonesia berupa mata air panas, tanah panas, fumarol, solfatara, geyser dan kolam lumpur panas. Selain itu, air tanah juga dapat menjadi panas akibat gesekan sepanjang bidang sesar, gradien panas batuan dan juga bahan - bahan radioaktif. Syarat utama Sistem geotermal terdiri dari tiga elemen utama: (1) batuan reservoir yang permeabel, (2) air yang membawa panas dari reservoir ke permukaan bumi, dan (3) sumber panas.

\section{Konfigurasi Shclumberger}

Konfigurasi Schlumberger merupakan salah satu konfigurasi yang sering digunakan dalam metode geolistrik yaitu dengan cara mengkondisikan spasi antar elektrode potensial adalah tetap sedangkan spasi antar elektrode arus berubah secara bertahap (Sheriff, 2002). Pada dasarnya untuk menentukan perubahan resistivitas tanah terhadap kedalaman maka dilakukan pengukuran ke arah vertikal atau Vertical Electrical Sounding (VES) tujuannya untuk memvariasikan resistivitas batuan di bawah permukaan bumi (Telford, et al., 1990). 


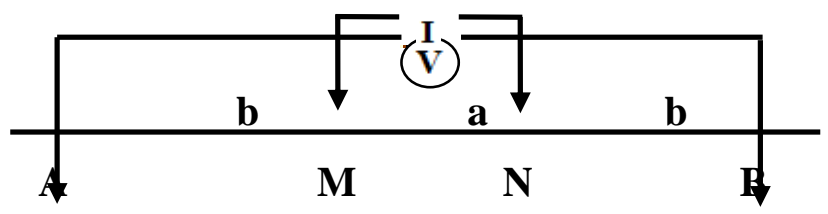

Gambar 1. Konfigurasi Schlumberger

Konfigurasi Schlumberger berlaku $\mathrm{OM}=\mathrm{ON}=1$ dan $\mathrm{OA}=\mathrm{OB}=1$, sehingga tahanan jenis semunya adalah:

$$
\rho_{s}=K_{s} \frac{\Delta V}{I}
$$

Dengan

$$
K_{s}=\frac{\pi\left(L^{2}-l^{2}\right)}{2 l}
$$

Idealnya jarak MN pada konfigurasi Schlumberger dibuat sekecil-kecilnya tujuannya agar secara teoritis jarak MN tidak berubah. Jika ingin merubah jarak MN karena keterbatasan kepekaan alat ukur tidak lebih besar dari 1/5 jarak AB.

\section{Peta Geologi Daerah Penelitian}

Secara stratigrafi daerah penelitian merupakan satuan perbukitan dan memiliki vegetasi lebat dan ada pula vegetasi jarang. Vegetasi yang jarang kebanyakan digunakan warga sebagai jalan menuju perkebunan sedangkan vegetasi yang lebat berupa rawa-rawa yang masih liar karena kurangnya aktivitas manusia di tempat tersebut. Berikut peta geologi regional daerah Gorontalo dan sekitarnya.

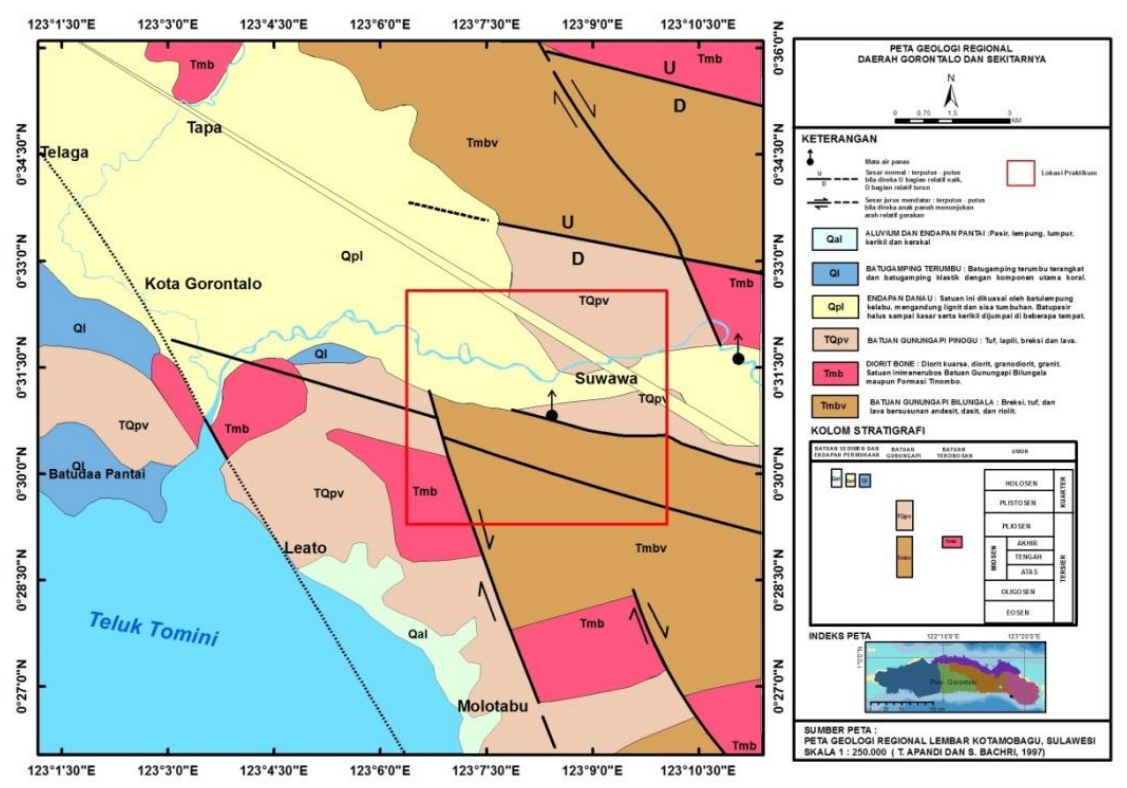

Gambar 2. Peta Geologi Regional Daerah Gorontalo dan sekitarnya 
Urutan stratigrafi Gorontalo terdiri dari batuan gunung api bilungala yang terdiri dari breksi, tuf lava bersusunan andesit, dasit, dan riolit. Ziolit dan kalsit sering di jumpai pada kepingan batuan penyusun breksi. Diorit bone terdiri dari diorit kuarsa, diorite, granodiorite, granit. Diorit kuarsa banyak dijumpai di daerah sungai Taludaa sedangkan granit utamanya di jumpai di daerah sungai Bone. Satuan ini menerobos batuan gunung api bilungala maupun farmasi tinombo. batuan gunung api terdiri dari tuf, tuf lapili, breksi dan lava. Endapan danau terdiri dari batu lempung kelabu, setempat mengandung sisa tumbuhan dan liknit. Batu gamping terumbu terdiri dari batu gamping terumbu terangkat dan batu gamping klstik.

\section{METODOLOGI PENELITIAN}

Penelitian ini dilakukan di desa Pancuran kecamatan suwawa selatan kabupaten Boalemo provinsi gorontalo koordinat $0^{0} 31^{\prime} 10,2^{\prime \prime} \mathrm{N} 123^{\circ} 8^{\prime} 41,3^{\prime \prime} \mathrm{E}$ pada bulan November 2016. Pengambilan data dilakukan di sekitar sumber mata air panas dengan menggunakan geolistrik konfigurasi Schlumberger. Alat dan bahan yang digunakan pada pengukuran sebagai berikut: (1) Seperangkat resistivity meter, (2) GPS, (3) Rol meter, (4) Palu geologi, (5) Peta geologi regional. Data yang diperoleh dari pengukuran berupa nilai arus, potensial dan hambatan jenis semu (resistivitas) selanjutnya pengolahan data menggunakan software IPI2WIN. Tahapan yang terakhir setelah proses pengolahan data yaitu interpretasi data lapangan untuk mendapatkan kondisi kedalaman dan nilai resistivitas. Untuk memperoleh hasil interpretasi yang lebih maksimal maka diperlukan data-data pendukung salah satunya peta geologi.

\section{HASIL PENELITIAN DAN PEMBAHASAN}

Gambar 3 dan 4 merupakan grafik pengolahan data menggunakan softwere IP2WIN dititik koordinat $0^{0} 31^{\prime} 10,2^{\prime \prime} \mathrm{N} 123^{0} 8^{\prime} 41,3^{\prime \prime} \mathrm{E}$.

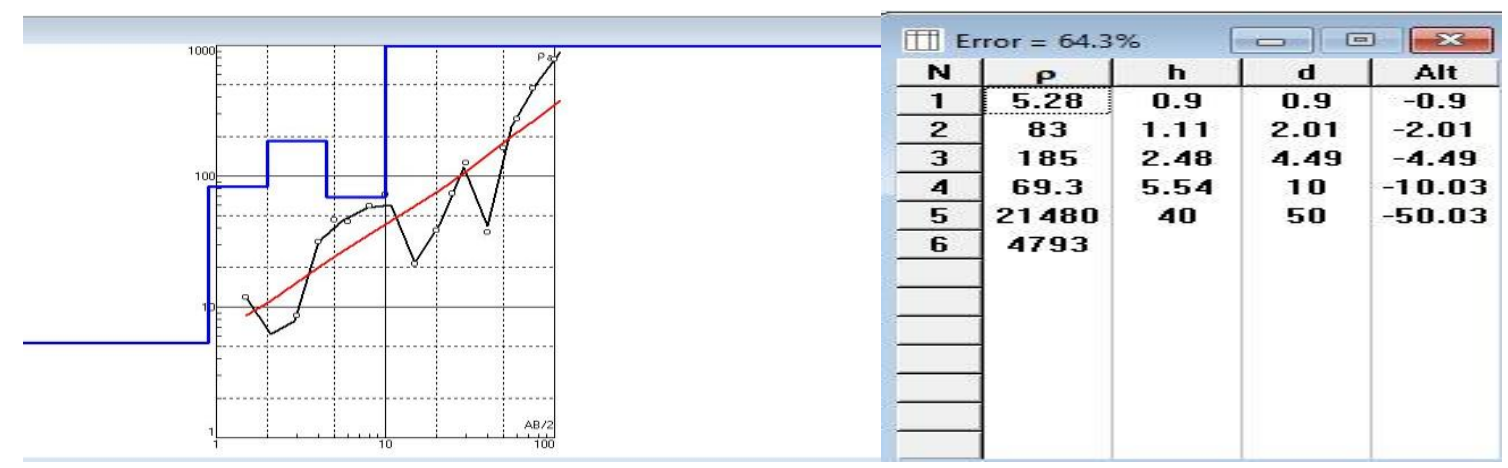

Gambar 3. Grafik hasil pengolahan data 


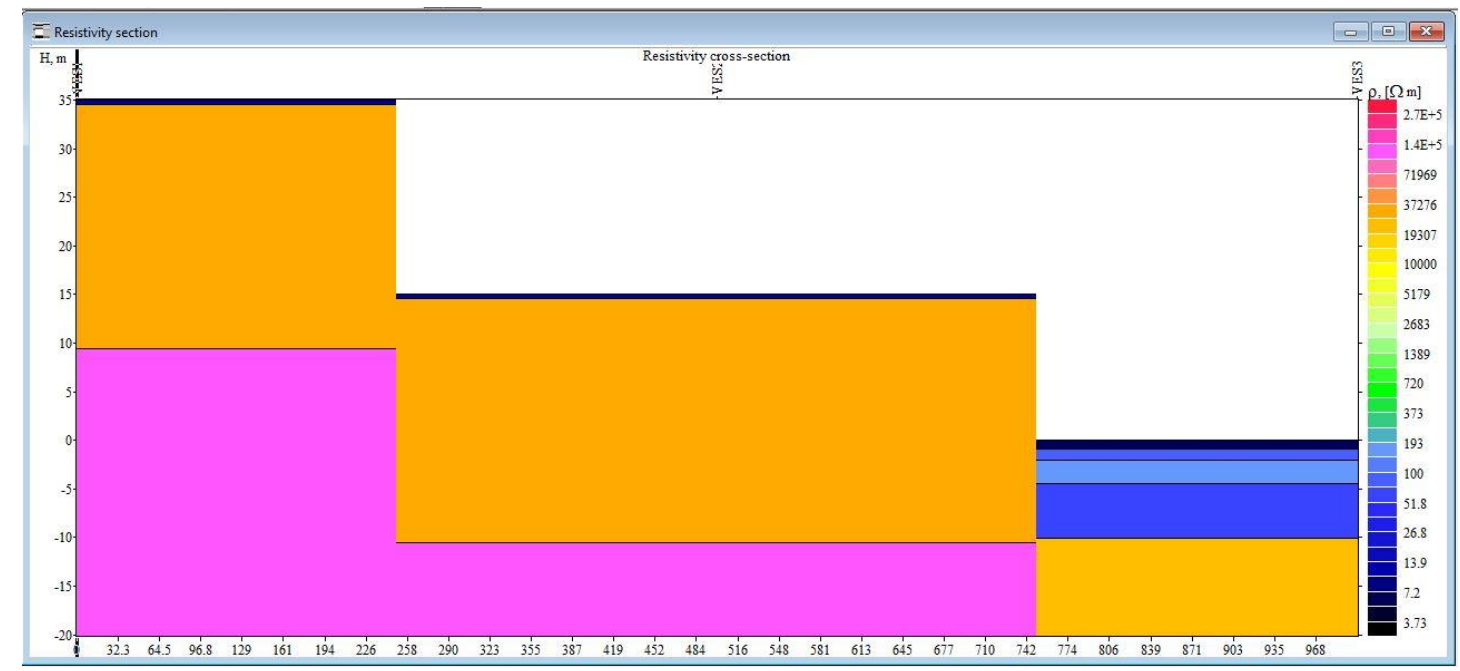

Gambar 4. Penampang resistivitas

Tabel 1 Hasil Interpretasi dengan Konfigurasi Schlumberger

\begin{tabular}{ccccc}
\hline Tahanan jenis & material & $\begin{array}{c}\text { Kedalaman } \\
(\mathrm{d})\end{array}$ & $\begin{array}{c}\text { Ketebalan } \\
(\mathrm{h})\end{array}$ & $\begin{array}{c}\text { Alt (elevasi 0 } \\
\text { mdpl) }\end{array}$ \\
\hline 5.28 & Lempung & 0.9 & 0.9 & -0.9 \\
83 & Batu pasir & 2.01 & 1.11 & -2.01 \\
185 & Batu pasir & 4,49 & 2,48 & $-4,49$ \\
69.3 & Batu pasir & 10 & 5.54 & -10.03 \\
21482 & andesit & 50 & 40 & -50.03 \\
\hline
\end{tabular}

Tabel 1 menunjukkan informasi tentang resistivitas, material, kedalaman dan ketebalan lapisan batuan. Lapisan pertama mempunyai nilai tahanan jenis sebasar 5,28 $\Omega \mathrm{m}$ serta memiliki ketebalan dan kedalaman yang sama besar yaitu sebesar 0,9 meter. Lapisan kedua memiliki tahanan jenis $83 \Omega$ m dengan meterial di dalamnya berupa batu pasir berada di kedalamam 2,01 meter dan tebal lapisan 1,11 m. Lapisan ketiga tahanan jenisnya $185 \Omega \mathrm{m}$ dengan material di dalamnya berupa batu pasir dengan kedalaman 4,49 meter, memiliki kedalaman 2,48 meter. pada lapisan ke empat tahanan jenisnya 69.3 meter dengan material di dalamnya berupa pasir dengan kedalaman 10 meter dengan ketebalan 5.54 meter. lapisan ke lima tahanan jenisnya 21482 dengan material didalamnya berupa andesit dengan kedalaman 50 meter dengan ketebalan 40 meter. 


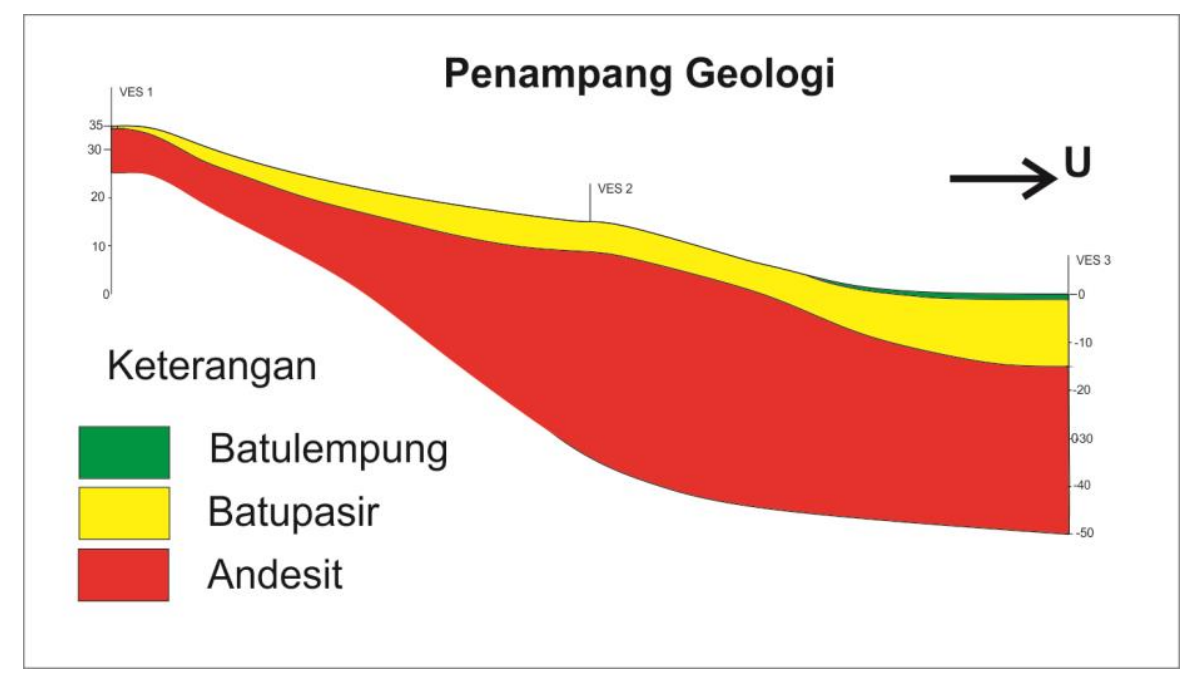

Gambar 5. Penampang Geologi

Berdasarkan gambar 5 dapat dilihat 3 lapisan batuan yaitu lempung, batu pasir dan andesit. Pada lapisan pertama terdapat lempung yang terdapat satuan pedataran yang terbentuk akibat aktivitas aluvial dengan ketebalan 0,9 m. Lapisan kedua yaitu batupasir yang dari arah selatan kemudian menuju ke utara yang semakin membesar penampang tersebut berwarna kuning dengan ketebalan $9 \mathrm{~m}$. Sedangkan pada lapisan ke tiga yaitu lapisan Andesit yang di tunjukkan gambar berwarna merah dari arah selatan mulai membesar ke arah utara dengan ketebatan $40 \mathrm{~m}$.

\section{KESIMPULAN}

Berdasarkan hasil penelitian struktur bawah permukaan dengan mengginakan metode geolistrik konfigurasi schlumberger didapatkan nilai resistivitas, kedalaman lapisan dan ketebalan batuan desa Pancuran yang terdiri dari 3 lapisan batuan yaitu lempung, batu pasir dan andesit. Lempung nilai resistivitas sebesar 5,28 $\Omega \mathrm{m}$ dengan ketebalan lapisan 0,9 m, batu pasir nilai resistivitas sebesar 69,3 $\Omega \mathrm{m}-185 \Omega \mathrm{m}$ dengan ketebalan lapisan sebesar 9 meter dan andesit memiliki ketebalan $40 \mathrm{~m}$ dengan nilai resistivitas sebesar $21482 \Omega \mathrm{m}$.

\section{REFERENSI}

Barber, A.J., Crow, M.J., De Smet, M.E.M, 2005, Sumatra: Geology, Resources and Tectonic Evolution, Geological Society Memoar, pp 234-257.

Franto, 2015, Interpretasi Struktur Geologi Regional Pulau Bangka Berdasarkan Citra Shuttle Radar Topography Mission (SRTM), Jurnal Promine, Vol 3 (1), Hal 10 20. 
Hochstein, M.P. dan Browne, P.R.L., 2000, Surface Manifestation of Geothermal System with Volcanic Heat Source, In Encyclopedia of Volcanoes, H. Siguardson, B.F. Houghton, S.R. Mc Nutt, H. Rymerdan J. Stix (eds.), Academic Press

Kearey, P., Brooks, M., Hill, I., 2002, An Introduction to Geophysical Exploration, Blackwell Publishing, London.

Minarto, E., 2007, Pemodelan Inversi Data Geolistrik untuk menentukan Struktur Perlapisan Bawah Permukaan Daerah Panasbumi Mataloko, Jurnal Fisika dan Aplikasinya, Vol.3, No.2.

Purwoto, E., Rezky, Y., Simarmata, R,S,L., 2015, Survey Aliran Panas (Heat Flow) Daerah Panas Bumi Permis Kabupaten Bangka Selatan, Provinsi Bangka Belitung, Pusat Sumber Daya Geologi, Bandung.

Siregar, R,N., 2015, Identifikasi Potensi Likuifaksi Pulau Bali Bagian Selatan Berdasarkan Data Ground Penetrating Radar (GPR), Geolistrik Resistivitas dan Pemboran Teknik, Tesis s FMIPA, Universitas Gadjah Mada, Yogyakarta.

Siregar, R,N., Sinarta, I, N., Ervan, M., Sismanto, 2016, Ground Penetrating Radar and 2D Electricity Application for Detecting Landslide in Abang District, Karangasem Regency, Bali, International Journal of Engineering Research and Applicantion , Vol. 6., Issue 7, (part-1) July 2016.

Surya, D., Bakrun, Arya, K., 2011, Penyelidikan Geofisika Terpadu Daerah Panas Bumi Maranda, Kabupaten Poso, Provinsi Sulawesi Tengah., Prosiding Hasil Kegiatan Pusat Sumber Daya Geologi Tahun 2011

Telford, M.W., Geldart L.P., Sheriff R.E., Keys D.A., 1990, Applied Geophysics, USA, Cambridge University Press.

Vargemezis, G., 2013, 3D geoelectrical model of geothermal spring mechanism derived from VLF measurements: A case study from Aggistro (Northern Greece), Geothermics, Vol. 51, pg 1-8. 